\title{
An adaptive scaffolding e-learning system for middle school students' physics learning
}

\author{
Ching-Huei Chen \\ National Changhua University of Education, Taiwan, Republic of China.
}

\begin{abstract}
This study presents a framework that utilizes cognitive and motivational aspects of learning to design an adaptive scaffolding e-learning system. It addresses scaffolding processes and conditions for designing adaptive scaffolds. The features and effectiveness of this adaptive scaffolding e-learning system are discussed and evaluated. An experiment was conducted within the domain of velocity and acceleration. The results revealed that the adaptive scaffolding system appeals to students and promotes improved performances and motivational outcomes. Specifically, the results suggested that learners with lower levels of knowledge who possessed extrinsic motivation benefited the most from the adaptive scaffolds. The implications of the design guidelines for developing personalized, adaptive scaffolding e-learning systems are discussed, and future research directions are recommended.
\end{abstract}

\section{Introduction}

Recently, researchers have called for the use of scaffolding to help students learn complex and abstract knowledge (Azevedo, Cromley, \& Seibert, 2004; Ge, Chen, \& Davis, 2005; Van den Boom, Paas, Van Merrienboer, \& Van Gog, 2004). A major reason for this call is that the development of human cognition is composed of a current level and a potential level, and that in between these is the zone of proximal development (ZPD) (Vygotsky, 1978). After accurately diagnosing students' current skill levels, we use scaffolding to advance their competence and to gradually hand the responsibility for learning to the students (Beed, Hawkins, \& Roller, 1991; Wood, Bruner, \& Ross, 1976). While several studies have lent support to the beneficial effect of scaffolding on student learning, their results showed that scaffolding must be supportive of students' learning tasks and must be adaptable to students' current level of understanding and affective state so that it can work within the students' prerequisite ZPD's (Chang \& Sun, 2009; Rosenshine \& Meister, 1992). Adaptive scaffolding reflects evidence that one size does not fit all (Reigeluth, 1996), and implies scaffolding should not only focus on student features such as cognitive status, but psychological traits that affect their learning. While human tutors have been found to be beneficial to students' learning, there is little empirical evidence to address situations in which no human tutor is immediately available (Akbulut \& Cardak, 2012). Moreover, the use of scaffolding adaptively to meet the needs of individuals with different levels of prior knowledge, real-world experience, and problem-solving competencies is still limited. Given this research gap, this study proposed an adaptive scaffolding e-learning system that mapped the right type of scaffolding to different learners to maximize the benefits of scaffolding, and conducted a summative evaluation to conclude the effectiveness and efficiency of such a system to students' learning and motivation. The findings of this study sought to contribute to the literature on learning with e-learning systems by demonstrating that externally regulated adaptive scaffolding mechanisms that aimed to facilitate students' progressions on motivation, were associated with superior performance gains during learning.

\section{Review of relevant literature}

Previous literature shows that it is possible to embed conceptual, metacognitive, and strategic hard scaffolds into traditional or technology-enhanced learning environments (e.g., Bulu \& Pedersen, 2010; Chen, 2010; Davis, 2003; Demetriadis, Papadopoulos, Stamelos, \& Fischer, 2008; Ge \& Land, 2003). Historically, hard scaffolds have been implemented in a fixed manner in which the assistance provided to students does not change based on their behavior. The effectiveness of hard scaffolds has not been consistently shown across disciplines or age groups. Many studies have found shortcomings in the use of hard scaffolds, including the inability to adapt to learners' needs, a lack of ongoing diagnosis, and failure to motivate learners to engage in deeper processing (Greene \& Land, 2000; Puntambekar \& Hubscher, 
2005; Rey, 2010). As a result, several researchers have argued for the importance of soft scaffolds, which are more dynamic and situational. Soft scaffolds provide just-in-time and personalized support for learners as they work (Azevedo, Moos, Greene, Winters, \& Cromley, 2008). The most common soft scaffolding role is that of the teacher, who is able to continuously diagnose the learners' understanding and provide timely support based on student responses (De Laat, Lally, Lipponen, \& Simons, 2007). However, in the context of computer-supported learning environments in which the teacher is outside of the learning process or is not immediately available, learners' engagement in and motivation to complete a task requiring mental effort decreases over time (Sins, Van Joolingen, Savelsbergh, \& Van Hout-Wolters, 2008; Whipp \& Chiarelli, 2004; Zhu, 2006). Therefore, a major interest for researchers and educators is examining how this type of learning environment can provide both dynamic and adaptive support for learners.

In recent years, research examining the development of adaptive educational systems has offered advanced forms of learning environments that attempt to meet the needs of different students (Akbulut \& Cardak, 2012; Diziol, Walker, Rummel, \& Koedinger, 2010; Magoulas, Papanikolaou, \& Grigoriadou, 2003; Mampadi, Chen, Ghinea, \& Chen, 2011; Peredo, Canales, Menchaca, \& Peredo, 2011; Tseng, Chu, Hwang, \& Tsai, 2008). In practical terms, adaptive systems build a model that is tailored to the learner's characteristics, knowledge, goals, learning style and preferences (e.g., Brusilovsky, 2001; Papanikolaou, Grigoriadou, Kornilakis, \& Magoula, 2003; Rasmussen \& Davidson-Shivers, 1998; Specht \& Oppermann, 1998). Peredo and his colleagues (2011) created an adaptive intelligent system that addresses the challenges of how the learning environment should change for learners with different characteristics using integrated tools as the basis for dynamically modeling learning characteristics and for designing instructional materials. Kelly (2008) used a multiple intelligence-based adaptive intelligent educational system to support learners with different learning characteristics and found improvements in learning performance and experience for learners with certain types of characteristics. Tseng and her colleagues (2008) adopted the learning style profiles and learners' behaviors from Keefe (1991) as the basis for developing an adaptive learning system. Their results showed that students' learning performances and their levels of efficiency improved with this innovative approach.

Although adaptive learning systems have shown promise in promoting learning outcomes, it is difficult to make claims about what makes adaptive learning systems effective. At the same time, we still hold little knowledge about which parts of adaptive learning systems benefit student learning, and to what extent adaptive learning systems affect students' learning behaviour and performance. Previous research generally indicates that positive results occur when individual differences and orientations of learning are taken into consideration when designing adaptive learning systems, but there is some evidence that adaptive learning may have negative aspects as well (e.g., Magoulas et al., 2003; Peredo et al., 2011; Tseng et al., 2008). Moreover, the majority of research focuses on pedagogical activities, such as adaptive presentations or navigational frameworks that are tailored to specific aspects of the teaching content (Hsiao, Sosnovsky, \& Brusilovsky, 2010; Mampadi et al., 2011). These studies have failed to investigate the notion of scaffolding on the promotion of students' cognition and motivation when acquiring conceptual knowledge. Additional attention should also be paid to providing individual and personalized scaffolds for positive motivational experiences, given that they benefit personalized learning (Kim, 2012). To sum up, most existing studies on adaptive learning have typically employed quasi-experimental designs, and thus did not have control over significant learner variables such as prior knowledge, motivation and so forth. The current study has employed a robust experimental design where the participants were assigned to different scaffoldings according to their prior knowledge and levels of motivation.

\section{Rationales for designing an adaptive scaffolding e-learning system}

Unlike other adaptive educational systems that were developed to adapt to different traits (i.e., learning styles or preferences), this study proposed an adaptive scaffolding system that supports learners' cognitive and motivational needs using Vygotsky's (1978) ZPD and Brophy's (1999) zone of motivational proximal development (ZMPD) theories. These theories serve as the basis for dynamically modeling learning characteristics and for designing instructional materials. Several studies have adopted Vygotsky's 
sociocultural theory as the basis for designing supportive strategies or tools to facilitate learning across different domains (e.g., Demetriadis et al., 2008; Doering \& Veletsianos, 2007; Ge \& Land, 2003; Graesser, McNamara, \& VanLehn, 2005; Land \& Zembal-Saul, 2003; Quintana, Meilan, \& Krajcik, 2005). In studies regarding scaffolding design to support learning, there is a consensus that scaffolding serves as temporary and adjustable assistance that can benefit the development of learners' cognitive skills. Yet, debate regarding whether scaffolding should be gradually withdrawn as learners gain competence remains unsolved. Bloom, Englehart, Frust, Hill and Krathwohl (1956) categorized the cognitive abilities of students into six components: knowledge, comprehension, application, analysis, synthesis, and evaluation. Each component is unique and is gradually developed through effective instruction. Because cognitive abilities are categorized hierarchically, it is assumed that students with low cognitive ability tend to lack the higher-level cognitive abilities, such as application, analysis, synthesis and evaluation, compared to high cognitive ability students (Bloom, 1956). It is feasible to use Bloom's taxonomy of the cognitive domains as the framework for scaffolding students' development of cognitive abilities (Granello, 2001).

Additionally, attention should also be paid to students' motivational needs. Brophy (1999) stated that most students who are given the appropriate resources, opportunities and environmental conditions, are likely to participate in class-related tasks and will exert more effort when completing them. Brophy (1999)'s ZMPD theory suggests that students' intrinsic motivation can be empowered and cultivated through scaffolding. To address the motivational needs of learners, a system should be designed to recognize the complexity of human motivation. Therefore, a model to help us better scale down the stages of motivation is necessary. Self-determination theory (SDT) (Deci \& Ryan, 1985; Ryan \& Deci, 2002) is a general theory of motivation that calls to systematically explicate the dynamics of human needs and motivation. SDT theorizes human motivation into three main categories: intrinsic motivation (doing something for itself, and the pleasure and satisfaction derived from participation), extrinsic motivation (doing something as a means to an end and not for their own sake), and amotivation (no intention to act or do something). Intrinsic regulation is at the most self-determined end of the continuum, which is when learners engage in activities solely for the enjoyment derived from the activity itself (Ryan \& Deci, 2000, 2002). The remaining forms of regulation are all considered extrinsic and run along the continuum of self-determination. Amotivation and extrinsic regulation are at the externally determined end of the continuum. Self-determination theory provides a clear view of motivational shifts and trends and echoes Brophy's (1999) ZMPD in that learners should experience scaffolding with appropriate motivational strategies that in turn facilitate sustained retention and effective transfer (Bransford, Brown, \& Cocking, 2000; Pintrich \& Schunk, 1996).

\section{Method}

\section{Participants and design}

A total of 170 eighth-grade students were recruited from four classes to participate in this study. The mean age of participants was 14.2 years $(\mathrm{SD}=1.25)$. Two classes were assigned as the experimental group and two classes as the control group. The experimental group, which included 81 students, was supported with the adaptive scaffolds, whereas the control group, which included 89 students, had access to the e-learning system but without additional support. We used a pre-test/post-test experimental research design to compare the performance of the groups with or without access to the adaptive scaffoldings in the e-learning system.

\section{Learning materials and context}

The domain of instruction was velocity and acceleration, a subject area of considerable complexity. Velocity and acceleration were chosen because while students are familiar with the terms, the concepts behind them are often difficult to teach, due to misconceptions and a reliance on prior knowledge. The instruction included five modules (a) speed and velocity, (b) uniform velocity and diagram, (c) acceleration movement, (d) uniform acceleration and diagram, (e) acceleration gravity. Further, each module included at least three to five topics. For example, the speed and velocity module involved four topics: object movement, average speed, instantaneous velocity, and speed. All instructional modules 
were presented across various multimedia formats, such as text, audio, animation, and video.

All the instructional modules were accessible to students through the adaptive scaffolding system and stored in a learning material database that only teachers or administers could add to or modify. Figure 1 illustrates the architecture of the adaptive scaffolding system. The student interface shows student model, presentation model, cognitive scaffold model, and motivational scaffold model. The different models have the following functions:

- The student model represents the background knowledge, characteristics and preferences of the learners. This static student model can retrieve the data from learner's profile information.

- The presentation model represents the learning materials that were developed based on the curriculum unit of a middle school natural science course. The objectives of the subject unit include the following: (a) explain the difference between velocity and acceleration, (b) solve problems involving projectile motion, and (c) find the velocity and acceleration of a vector-valued function. This model also manages the flow of information and monitors interactions between the learner and the system.

- A cognitive scaffold model represents the characteristics that are involved in determining the learners' cognitive levels. This model uses artificial intelligence techniques to dynamically diagnose learners' cognitive levels (i.e. high, medium, and low), and the system uses this information to determine what type of scaffold to present to the student next. Cognitive scaffolds include three types: knowledge, application, and synthesis. The system detects students' understandings of the concepts and determines whether learners stay at the same cognitive level, advance to the next cognitive level, or even devolve to a lower cognitive level.

- A motivational scaffold model represents individualized motivating strategies, which include direct access to features that support efforts to motivate learners that are highly adaptive based on learners' identified needs and circumstances. This model uses artificial intelligence techniques to dynamically diagnose learners' motivational levels (i.e. 1, 2, and 3), and the system uses this information to determine what type of scaffold to present to the student next. Scaffolds include three types: intrinsic, external, and amotivation. Scaffolds are text-based messages that encourage the regulation of learning and address the importance or relevance of knowledge to the learners. The intrinsic motivation scaffold focuses on explicitly taking values, goals, and structures as one's own. The external motivation scaffold helps reduce the learners' feelings of internal pressure, guilt, and shame with contingencies regarding self-worth. With this scaffold, learners focus on making the information personally meaningful and important. The amotivation scaffold directs learners' attention towards engaging in a behavior for instrumental reasons (i.e., obtaining better grades). The examples of cognitive and motivational scaffolds are provided in Table 1.

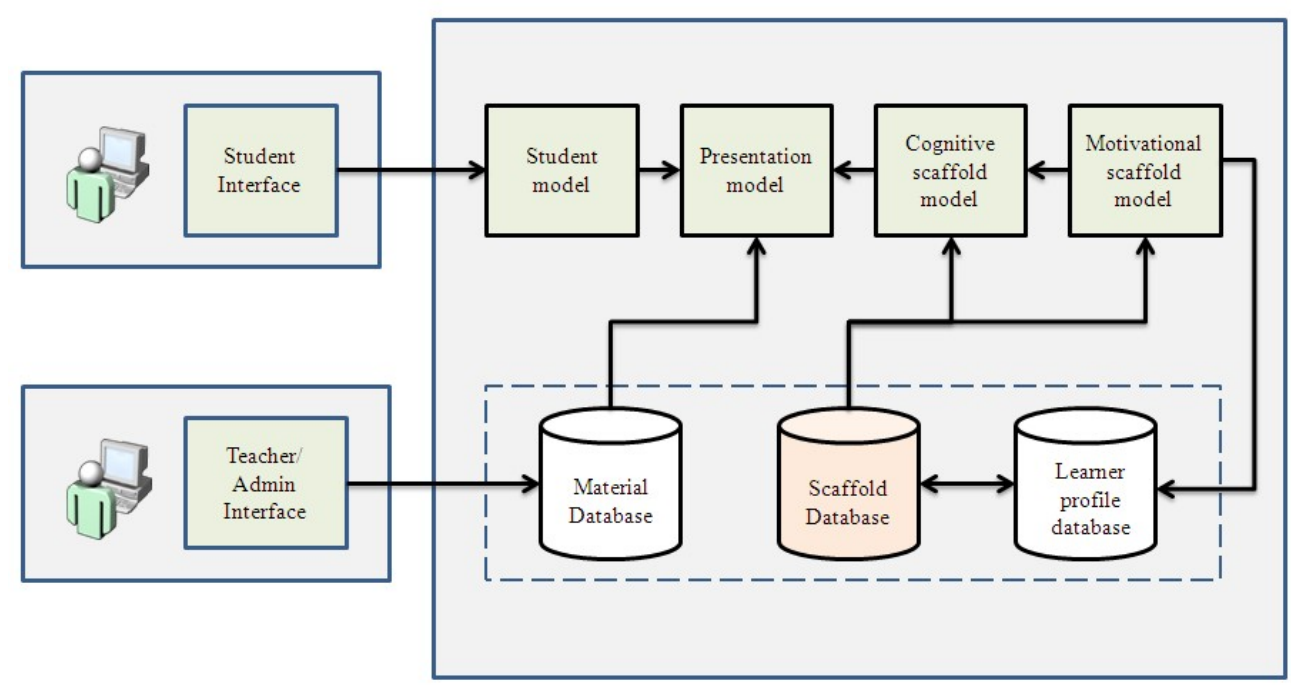

Figure 1. Architecture of adaptive scaffolding system 
Table 1.

Examples of cognitive and motivational scaffolds for Instructional Module 1: Speed and Velocity

\begin{tabular}{|c|c|c|c|c|}
\hline Topics & $\begin{array}{l}\text { Cognitive } \\
\text { levels }\end{array}$ & Cognitive scaffolds & $\begin{array}{l}\text { Motivational } \\
\text { levels }\end{array}$ & Motivational scaffolds \\
\hline \multirow[t]{3}{*}{$\begin{array}{l}\text { Object } \\
\text { movement }\end{array}$} & Knowledge & $\begin{array}{l}\text { Moving objects don't always travel with erratic and } \\
\text { changing speeds. Occasionally, an object will move at a } \\
\text { steady rate with a constant speed. }\end{array}$ & Intrinsic & $\begin{array}{l}\text { The concept of object movement will lead to the next lesson } \\
\text { "Average speed" where you will learn to calculate the average } \\
\text { speed during a course of motion. }\end{array}$ \\
\hline & Application & $\begin{array}{l}\text { Moving object will cover the same distance every regular } \\
\text { interval of time. For instance, a cross-country runner might } \\
\text { be running with a constant speed of } 6 \mathrm{~m} / \mathrm{s} \text { in a straight line } \\
\text { for several minutes. }\end{array}$ & Extrinsic & $\begin{array}{l}\text { We can observe cars move at a steady rate with a constant } \\
\text { speed. That is, the object will cover the same distance every } \\
\text { regular interval of time. }\end{array}$ \\
\hline & Synthesis & $\begin{array}{l}\text { If the object's speed is constant, then the distance traveled } \\
\text { every second is the same. An object with a changing speed } \\
\text { would be moving a different distance each second. }\end{array}$ & Amotivation & $\begin{array}{l}\text { Everyday, most of us use some form of transportation to get } \\
\text { somewhere. Understand the concept of object movement can } \\
\text { help figuring out how long it will take us to go from one place } \\
\text { to another. }\end{array}$ \\
\hline \multirow[t]{3}{*}{$\begin{array}{l}\text { Average } \\
\text { speed }\end{array}$} & Knowledge & $\begin{array}{l}\text { Average speed is used to give the speed of an object over a } \\
\text { given interval of time, if however the speed of an object is } \\
\text { required for a particular moment then the instantaneous } \\
\text { speed is used. }\end{array}$ & Intrinsic & $\begin{array}{l}\text { The concept of average speed will lead to the next lesson } \\
\text { "Instantaneous speed" where you will learn to understand the } \\
\text { distance per time ratio. }\end{array}$ \\
\hline & Application & $\begin{array}{l}\text { A lobster creeps } 10 \mathrm{~m} \text { along the sea bed in } 5 \text { minutes. } \\
\text { Find its average speed. As learned, the formula is average } \\
\text { speed=distance } / \text { time. Entering our numbers: } \\
\text { average speed }=10 \div(5 \times 60) \\
=10 \div 300=0.033 \mathrm{~m} / \mathrm{s}(=3.3 \mathrm{~cm} / \mathrm{s})\end{array}$ & Extrinsic & $\begin{array}{l}\text { Calculating average speed is common in our daily life. } \\
\text { Examples: moving at five kilometers per hour, it will take us } \\
\text { eight hours to get to the base camp. }\end{array}$ \\
\hline & Synthesis & $\begin{array}{l}\text { A car cruises at an average speed of } 50 \text { miles per hour. } \\
\text { How much time will it take to go } 600 \text { miles? } \\
\text { The formula is: Average speed=distance/time. Entering our } \\
\text { numbers: } 50=600 \div \text { time. } \\
\text { Time }=600 \div 50=12 \text { hours }\end{array}$ & Amotivation & $\begin{array}{l}\text { Whether a car, bus, a bicycle, or our own two feet, } \\
\text { understanding how to calculate average speed is important in } \\
\text { today's world of schedules and time crunches. The race track is } \\
\text { a place where speed is especially important. }\end{array}$ \\
\hline
\end{tabular}


Table 1. (cont...)

\begin{tabular}{|c|c|c|c|c|}
\hline \multirow[t]{3}{*}{$\begin{array}{l}\text { Instantaneous } \\
\text { speed }\end{array}$} & Knowledge & $\begin{array}{l}\text { The instantaneous speed of an object is not to be confused with } \\
\text { the average speed. Average speed is a measure of the distance } \\
\text { traveled in a given period of time. Suppose that during your trip } \\
\text { to school, you traveled a distance of } 5 \text { miles and the trip lasted } \\
0.2 \text { hours ( } 12 \text { minutes). The average speed of your car could be } \\
\text { determined as Average speed }=5 \mathrm{miles} / 0.2 \text { hours }=25 \mathrm{miles} / \mathrm{hour} \text {. }\end{array}$ & Intrinsic & $\begin{array}{l}\text { Instantaneous velocity is not a tricky concept. Most problems ask } \\
\text { about an object's instantaneous velocity rather than its average } \\
\text { velocity or speed over a given time frame. Unless a question } \\
\text { specifically asks you about the average velocity or speed over a } \\
\text { given time interval, you can safely assume that it is asking about } \\
\text { the instantaneous velocity at a given moment. }\end{array}$ \\
\hline & Application & $\begin{array}{l}\text { Instantaneous velocity has a magnitude and a direction, and } \\
\text { deals with the velocity at a particular instant in time. "The } \\
\text { cheetah can run at } 70 \text { miles per hour" is an example of } \\
\text { instantaneous speed. }\end{array}$ & Extrinsic & $\begin{array}{l}\text { You might think of the instantaneous speed as the speed that the } \\
\text { speedometer reads at any given instant in time and the average } \\
\text { speed as the average of all the speedometer readings during the } \\
\text { course of the trip. Since the task of averaging speedometer } \\
\text { readings would be quite complicated (and maybe even } \\
\text { dangerous). }\end{array}$ \\
\hline & Synthesis & $\begin{array}{l}\text { Instantaneous speed is the speed of an object at a given } \\
\text { moment. In this case the equation is similar to that of average } \\
\text { speed but the time taken is a much smaller interval. A } \\
\text { speedometer in the car gives an instantaneous speed as it gives } \\
\text { the speed of the moving car at that specific time, whereas the } \\
\text { average speed would be used as a measure of speed for the } \\
\text { whole journey. }\end{array}$ & Amotivation & $\begin{array}{l}\text { The speed at any instant of time is known as instantaneous speed. } \\
\text { With a car's speedometer, we are interested in the instantaneous } \\
\text { velocity or speed at a given moment. That is, we want to know } \\
\text { how fast that object is moving right now. }\end{array}$ \\
\hline \multirow[t]{3}{*}{ Speed } & Knowledge & $\begin{array}{l}\text { Speed is defined as a measure of the distance an object travels } \\
\text { in a given length of time. }\end{array}$ & Intrinsic & $\begin{array}{l}\text { Speed is a scalar quantity that refers to "how fast an object is } \\
\text { moving." In this lesson, you should have the basic understanding } \\
\text { of what speed is and the means for calculation and composition of } \\
\text { various average speeds. This basic understanding is important to } \\
\text { the future lesson on position-time graph for the object. }\end{array}$ \\
\hline & Application & $\begin{array}{l}\text { Speed and velocity only deal with movement at a constant rate. } \\
\text { When we speed up, slow down, or change direction, we want to } \\
\text { know our acceleration. Acceleration is a vector quantity that } \\
\text { measures the rate of change of the velocity vector with time. }\end{array}$ & Extrinsic & $\begin{array}{l}\text { Speed can be thought of as the rate at which an object covers } \\
\text { distance. A fast-moving object is contrasted to a slow-moving } \\
\text { object in terms of their speeds, and an object with no movement } \\
\text { at all has a zero speed. }\end{array}$ \\
\hline & Synthesis & $\begin{array}{l}\text { Speed can be thought of as the rate at which an object covers } \\
\text { distance. A fast-moving object has a high speed and covers a } \\
\text { relatively large distance in a short amount of time. Contrast this } \\
\text { to a slow-moving object that has a low speed; it covers a } \\
\text { relatively small amount of distance in the same amount of time. }\end{array}$ & Amotivation & $\begin{array}{l}\text { Calculating average speed can help to predict the outcome of a } \\
\text { race. For example, How long would it take to get to the moon } \\
\text { using your feet, a car, or light beam? If you know the distance it } \\
\text { traveled and the length of time it took to travel that distance, you } \\
\text { can easily solve this question. }\end{array}$ \\
\hline
\end{tabular}


In addition to the student interface, the teacher/admin interface allows teachers and administers to access the learning materials, scaffolds, and learner profile databases. The material database allows teachers to upload or modify the instructional modules. The scaffold database allows teachers to add or modify cognitive and motivation scaffolds. In the learner profile database, the teachers can check on the status of each student as well as their learning profile.

\section{Measurements}

\section{Domain-specific conceptual knowledge test}

In order to develop an instrument to measure students' conceptual understanding of velocity and acceleration, a list of misconceptions identified by two subject matter experts was first extracted. The knowledge test included three types: knowledge, application, and synthesis. The instructional materials comprised five modules consisting of 19 topics. Each topic covered three types of knowledge test. As a result, a 57-item multiple-choice knowledge test was created to diagnose student misconceptions in velocity and acceleration (contact author for sample questions). The knowledge test was reviewed, revised, and validated by two eighth-grade science teachers. The knowledge test was administered twice-pre-test and post-test; the maximum achievable score in each case being 57 . The tests were analyzed for internal consistency using the Kuder-Richardson Formula 20. The reliability coefficients were .81 and .84 for the pre-test and post-test, respectively.

\section{Motivational scale}

A slightly modified version of Vallerand et al.'s (1992) Academic Motivation Scale (AMS) was used to measure five distinct constructs: amotivation, external regulation, introjected regulation, identified regulation, and intrinsic motivation. The final scale consisted of the following three types of motivation: intrinsic motivation, extrinsic motivation, and amotivation. Intrinsic motivation was measured with seven subscales, each containing four items that were further categorized into the intrinsic motivation to know, to accomplish, and to experience stimulation, for a total of three subscales with 12 items. Extrinsic motivation involved external, introjected, and identified regulations, each of which included 4 items, for a total of 12 items. Amotivation also had four items. A reliability test indicated that our final AMS scale has satisfactory internal consistency across subscales, ranging from .72 to .94. To obtain each student's motivational profile, Grolnick and Ryan (1987) proposed the calculation of Relative Autonomy Index (RAI) to represent students' motivational profiles. A student's motivational profile is calculated using the following formula: $($ External $*(-2))+($ Introjected $*(-1))+($ Identified $*(1))+($ Intrinsic * (2)) .

\section{Procedure}

A diagram of the research procedure is presented in Figure 2. The students were first assigned to either experimental or control groups. All participants in each group were individually tested in a computer lab and completed the pre-test and the motivational scale. Next the researcher provided instructions for the learning task and helped both groups' participants become familiar with the learning system. The major distinction between experimental and control groups was the accessibility to cognitive and motivational scaffold models. The experimental phase was conducted over a 3 week period, entailing 120 minutes per week. During the experiment, students in the experimental groups had access to scaffold models after studying each module's multimedia content. Before studying the next module, each student was evaluated on his or her cognitive and motivational levels. Formatively assessing students in the learning process allowed the system to determine what kinds of scaffolds should be given to them before the next module began. After completing the experiment, all students in the two groups completed the post-test and the motivational scale. 


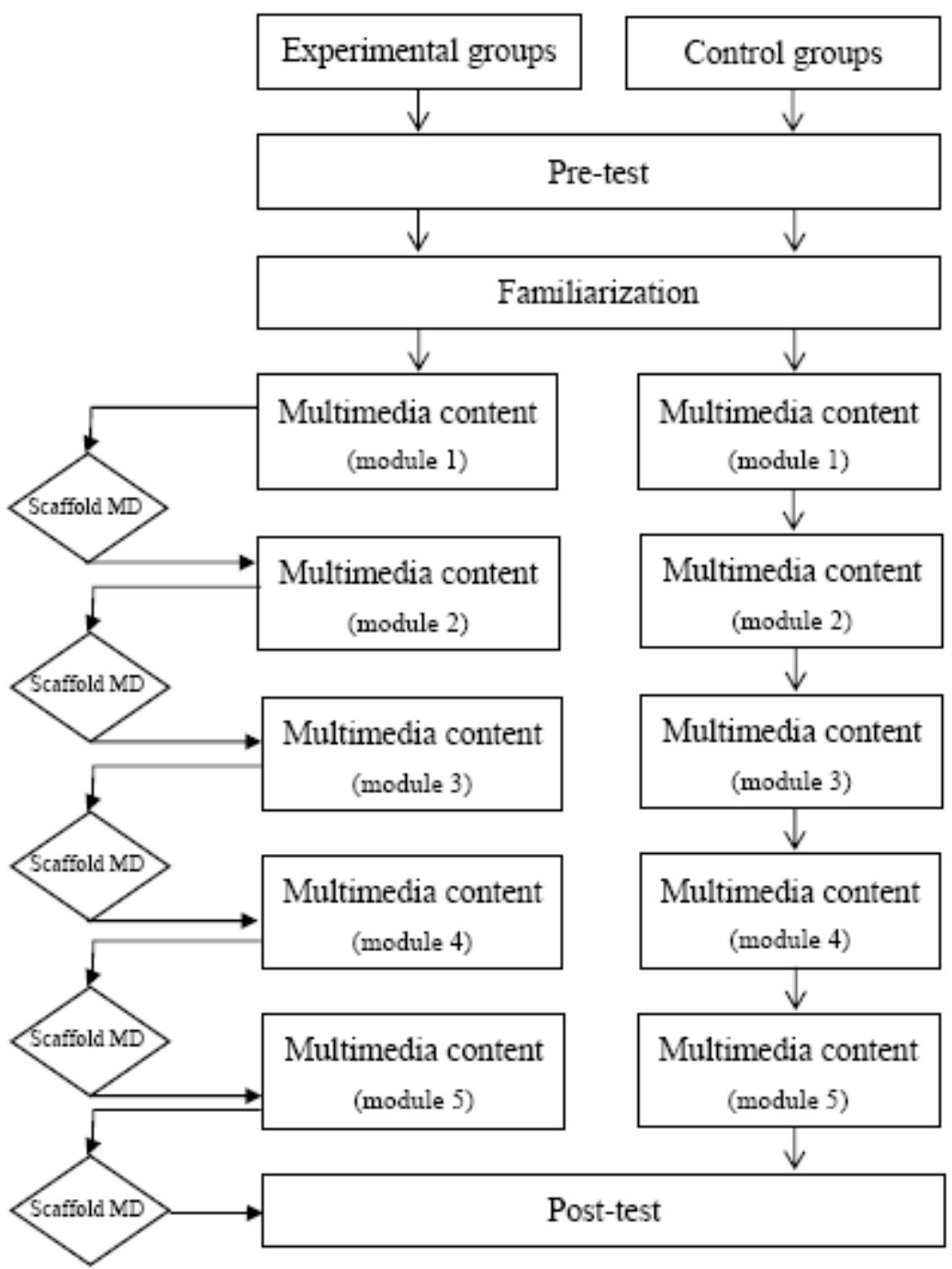

Figure 2. Research procedure

\section{Results}

\section{Student performance}

We used an ANCOVA (analysis of covariance) to treat the pre-test scores as a covariate. A test of homogeneity showed that the regression slopes of the two conditions were homogeneous $(F=2.78, p=.13)$, which established that the data were suitable to use in an ANCOVA. Table 2 illustrates that the post-test scores differed significantly between two conditions $\left(F[2,170]=5.07\right.$, MSE $\left.=297.03, p<.05, \eta^{2}=.15\right)$, and that students in the experimental group achieved higher scores $(\mathrm{M}=41.33, \mathrm{SD}=5.47)$ than those in the control group $(\mathrm{M}=37.16, \mathrm{SD}=5.81)$. Thus, we can conclude that the adaptive scaffolding e-learning system led to improved learning performance. 
Table 2.

Descriptive statistics of student performance and motivation scale

\begin{tabular}{lllll}
\hline & \multicolumn{2}{l}{ Experimental Group $(\mathrm{N}=81)$} & \multicolumn{2}{l}{ Control Group (N=89) } \\
\cline { 2 - 5 } & $\mathrm{M}$ & $\mathrm{SD}$ & $\mathrm{M}$ & $\mathrm{SD}$ \\
\hline Pre-test & 34.17 & 4.76 & 33.81 & 5.57 \\
Post-test & 41.33 & 5.47 & 37.16 & 5.81 \\
Motivational scale & 7.63 & 1.56 & 5.81 & 0.16 \\
\hline
\end{tabular}

To understand how the adaptive learning system benefited students with different levels of prior knowledge, the researcher further divided students into three sub-groups based on their pre-test scores, which ranged from 17-51 (M=33.99) out of a possible 57. Students with low prior knowledge (bottom one-third; LPK group) were compared with students with high prior knowledge (top one-third; HPK group). The students in the middle one-third, with a middle range of prior knowledge were analyzed as middle prior knowledge (MPK group). Table 3 compares pre- and post-test results for students in each of these three sub-groups. A one-way ANOVA showed that there was a significant difference in the experimental group $\left(F[3,170]=14.26, \mathrm{p}<.05, \eta^{2}=.16\right)$ on the post-test scores. The following post-hoc analysis further revealed that LPK group gained a significant improvement relative to the HPK and MPK groups.

Table 3.

Student performance on the post-test according to pre-test

\begin{tabular}{|c|c|c|c|c|c|c|c|c|c|c|c|c|}
\hline & \multicolumn{6}{|c|}{ Experimental group } & \multicolumn{6}{|c|}{ Control group } \\
\hline & \multicolumn{2}{|c|}{$\operatorname{HPK}(\mathrm{N}=19)$} & \multicolumn{2}{|c|}{$\operatorname{MPK}(\mathrm{N}=33)$} & \multicolumn{2}{|c|}{$\operatorname{LPK}(\mathrm{N}=29)$} & \multicolumn{2}{|c|}{ HPK $(\mathrm{N}=23)$} & \multicolumn{2}{|c|}{$\operatorname{MPK}(\mathrm{N}=37)$} & \multicolumn{2}{|c|}{$\operatorname{LPK}(\mathrm{N}=29)$} \\
\hline & M & SD & M & SD & M & SD & M & SD & M & SD & M & SD \\
\hline Pre-test & 47.32 & 4.71 & 35.78 & 4.10 & 19.43 & 4.57 & 46.53 & 4.98 & 33.27 & 5.10 & 21.65 & 4.93 \\
\hline Post-test & 53.75 & 5.10 & 40.10 & 5.91 & 30.16 & 5.30 & 48.29 & 5.10 & 38.41 & 4.98 & 24.78 & 5.89 \\
\hline
\end{tabular}

\section{Student motivational profile}

We used an ANCOVA to treat the prior motivational profile scores as a covariate. A test of homogeneity showed that the regression slopes of the two conditions were homogeneous $(\mathrm{F}=1.89, \mathrm{p}=.09)$, which established that the data were suitable to use in an ANCOVA. A significant main effect between the two groups was found regarding student motivation $\left(F[2,170]=4.01, \mathrm{MSE}=78.89, \mathrm{p}<.05, \eta^{2}=.08\right)$, with students in the adaptive scaffolding condition achieving higher scores than students in the control condition. Thus, we can conclude that the adaptive scaffolding e-learning system improved students' learning motivation.

\section{Discussion}

\section{Summary}

In this study, we proposed an adaptive scaffolding mechanism to address students' cognitive and motivational needs to promote personalized learning in an online learning environment. Automated, dynamic, and adaptive support was promoted by gradually diagnosing the interactions between individual students and the instructional content provided. The strategies used during the adaptive scaffolding were constructed to support cognitive development, geared toward increasing positive motivation, and based on theories and prior research on adaptive learning (Graesser et al., 2005; Lajoie \& Azevedo, 2006). The availability and customizability of these scaffoldings enabled the strategies to be provided in real-time and to be customized for the individual students. Given the results regarding students' performance and motivation, the adaptive scaffolding system was appealing to students and promoted their motivational 
outcomes. Compared to students who did not use this system, those who did were able to gain a better understanding of the complex scientific concepts presented and showed sustained motivation. The main empirical effect of this study can be related to the attribution and goal orientation theories by providing useful scaffolding to help students understand their motivation and personalize their choice of educational activities (Ames, 1992; Weiner, 1990). The application of the concept of adaptive scaffolding e-learning systems is that matching the delivery of learning material to students' cognitive and motivation levels should improve their learning experience. In addition, our adaptive e-learning system was inspired by the work of Vygotsky in the sense that it models the student's zone of proximal development in order to scaffold the learning process, particularly by suggesting help and increasing complex task levels to individual students. In effect, it acts as a virtual yet more able learning partner that suggests and supports additional learning activities that are just beyond the students' independent ability level (Akbulut \& Cardak, 2012; Azevedo et al., 2004; Lo, Chan, \& Yeh, 2012; Shute \& Towle, 2003). Furthermore, this study presents the design process for an adaptive motivational scaffold that allows students to draw explicit connections between the learned materials and their personal lives, and it allows an unlimited number of attempts to familiarize students with the content until they are satisfied. This design process indicates how motivation was conceptualized and then made explicit in the adaptive e-learning system. As a result, this study suggests the adaptive scaffolding e-learning system can be a valid tool for gaining students' conceptual knowledge and promoting inner motivation towards meaningful goals.

In recent years, a growing body of research has examined the influence of prior knowledge in hypermedia learning systems (e.g., Amadieu, Tricot, \& Marine, 2009; Magoulas et al., 2003; Park, Lee, \& Kim, 2009; Shapiro, 1999). This study explored the interactive effects between different scaffolds and different learner variables, suggesting a need to design scaffolds adaptively to meet the needs of individuals with different levels of prior knowledge. This aligns with previous findings with respect to the interaction between prior knowledge and levels of scaffolds (Ge et al., 2005; MacGregor \& Lou, 2004; Sins, Savelsbergh, \& Van Joolingen, 2005). Furthermore, this study revealed that prior knowledge can determine how well learners acquire information from e-learning systems and ultimately influence their learning outcomes in e-learning systems. Building on previous findings that adaptive scaffoldings can regulate student's learning process (Azevedo et al., 2004), this study also found a relationship between students' prior knowledge and learning outcome when using adaptive scaffoldings, whereby students with lower levels of prior knowledge showed greater levels of improvement in their learning outcome than those with medium to high levels of prior knowledge.

\section{Implications}

In conventional web-based learning environments, a fixed learning sequence and content for all students without considering the diverse needs of each individual is often implemented. Research in general has focused on using adaptive content or strategies to facilitate the teaching-learning process. When using adaptive learning systems, learning processes are more effective and successful because the instructional approaches and content are adapted to individual learners. This study indicates that adaptive scaffolding is a holistic and integrated approach that supports learners in the accomplishment of their learning goals by aligning the learning process with the personal cognitive attributes of the learners. According to Vygotsky's ZPD, scaffolding is an integral part of the meaning making process. This study illustrates that students' cognitive and affective backgrounds need to be relevantly included and built upon during the learning such that they are connected to students' ZPD. As a result of such integration, students' conceptions of their capability to learn were re-defined and nurtured. While most of the adaptive e-learning systems take into account students' learning styles, gender, and cognitive demands (e.g., Kenny \& Pahl, 2009; Peredo et al., 2011; Tseng et al., 2008), this study suggests that cultivating positive motivation and reducing negative motivation can benefit learning processes and outcomes. Moreover, some implementations for the adaptive learning system used here could be further enhanced to foster students' learning performance and motivation. First of all, cognitive and motivational scaffolds should be provided automatically by the system to allow students in monitoring their own learning status. Second, formative assessments could be added to the system to stimulate the interactions between the instructional materials and students. Although the learning issues in this study were around the concepts of velocity and acceleration, this study provides design principles for developing effective adaptive scaffolds and 
ways of integrating these scaffolds into e-learning systems that should be applicable to a range of other content domains.

In addition, this study suggests that promoting positive learning outcomes requires taking into account students' prior knowledge. Since prior knowledge can have a significant impact on learning processes and outcomes, when designing scaffolds, educators should keep in mind that offering appropriate support for each individual determines whether it improves students' performance and motivation. Thus, scaffolds for students with lower levels of prior knowledge should be dynamic in order to best assist them to actively construct knowledge.

\section{Limitations and suggestions for future research}

The current study has several important limitations. First, the data collected were cross-sectional, and there is a need for additional longitudinal research to test the relationship among the variables investigated in this study. The second limitation of this study, which was a practical necessity borne out of working with classroom cohorts of students, is that participants were assigned to the treatment or control groups based on their classroom affiliations rather than at random. Several future research possibilities exist, including questions regarding the incorporation of other cognitive profiles of learners-such as the need for cognitive or inductive reasoning skills - and the investigation of correlations between these profiles and their effects on performance and motivation. This study uses self-determination theory as the design guideline for creating an adaptive scaffolding mechanism. Future research could instead adopt other existing models and theories, such as Keller's (2010) ARCS (Attention, Relevance, Confidence, and Satisfaction) or Astleitner's (2000) FEASP (Fear, Envy, Anger, Sympathy, and Pleasure). In summary, this study takes an initial step toward extending and validating adaptive learning that affects cognitive and motivational factors in a technologically enhanced learning environment.

\section{References}

Akbulut, Y., \& Cardak, C. S. (2012). Adaptive educational hypermedia accommodating learning styles: A content analysis of publications from 2000 to 2011. Computers \& Education, 58(2), 835-842. doi: 10.1016/j.compedu.2011.10.008

Amadieu, F., Tricot, A., \& Marine, C. (2009). Prior knowledge in learning from a non-linear electronic document: Disorientation and coherence of the reading sequences. Computers in Human Behavior, 25, 381-388.

Ames, C. (1992). Classrooms goals structures and student motivation. Journal of Educational Psychology, $84,261-271$.

Astleitner, H. (2000). Designing emotionally sound instruction: The FEASP-approach. Instructional Science, 28(3), 169-198.

Azevedo, R., Cromley, J. G., \& Seibert, D. (2004). Does adaptive scaffolding facilitate students' ability to regulate their learning with hypermedia? Contemporary Educational Psychology, 29, 344-370.

Azevedo, R., Moos, D. C., Greene, J. A., Winters, F. I., \& Cromley, J. G. (2008). Why is externally-facilitated regulated learning more effective than self-regulated learning with hypermedia? Educational Technology Research and Development, 56, 45-72.

Beed, P., Hawkins, M., \& Roller, C. (1991). Moving learners toward independence: The power of scaffolded instruction. The Reading Teacher, 44(9), 648-655.

Bloom, B. S. (1956). Taxonomy of educational objectives, the classification of educational goals. New York: McKay

Bloom, B. S., Englehart, M. D., Frust, E. J., Hill, W. H., \& Krathwohl, D. R. (1956). Taxonomy of educational objectives, Handbook I: Cognitive domain. New York: Longmans, Green.

Bransford, J. D., Brown, A. L., \& Cocking, R. R. (2000). How people learn: Brain, mind, experience, and school. Washington, DC: National Academy Press.

Brophy, J. (1999). Toward a model of value aspects of motivation in education: Developing appreciation for particular learning domains and activities. Educational Psychologist, 34(2), 75-85. 
Brusilovsky, P. (2001). Adaptive hypermedia. User Modeling and User-Adapted Instruction, 11(1-2), 87-110.

Bulu, S., \& Pedersen, S. (2010). Scaffolding middle school students' content knowledge and ill-structured problem solving in a problem-based hypermedia learning environment. Educational Technology Research \& Development, 58(5), 507-529. doi: 10.1007/s11423-010-9150-9

Chang, W.-L, \& Sun, Y-C. (2009). Scaffolding and web concordancers as support for language learning. Computer Assisted Language Learning, 22(4), 283-302.

Chen, C.-H. (2010). Promoting college students' knowledge acquisition and ill-structured problem solving: Web-based integration and procedure prompts. Computers \& Education, 55(1), 292-303.

Davis, E. A. (2003). Prompting middle school science students for productive reflection: Generic and directed prompts. The Journal of the Learning Sciences, 12(1), 91-142.

De Laat, M., Lally, V., Lipponen, L., \& Simons, R. (2007). Online teaching in networked learning communities: A multi-method approach to studying the role of the teacher. Instructional Science, 35, 257-286.

Deci, E.L., \& Ryan, R.M. (1985). Intrinsic motivation and self-determination in human behavior. New York: Plenum.

Demetriadis, S., N., Papadopoulos, P. M., Stamelos, I. G., \& Fischer, S. (2008). The effect of scaffolding students' context-generating cognitive activity in technology-enhanced case-based learning. Computers \& Education, 51, 939-954.

Diziol, D., Walker, E., Rummel, N., \& Koedinger, K. R. (2010). Using intelligent tutor technology to implement adaptive support for student collaboration. Educational Psychology Review, 22(1), 89-102. doi: $10.1007 /$ s10648-009-9116-9

Doering, A., \& Veletsianos, G. (2007). Multi-scaffolding learning environment: An analysis of scaffolding and its impact on cognitive load and problem-solving ability. Journal of Educational Computing Research, 37(2), 107-129.

Ge, X., Chen, C.-H., \& Davis, K. A. (2005). Scaffolding novice instructional designers' problem-solving processes using question prompts in a web-based learning environment. Journal of Educational Computing Research, 33(2), 219-248.

Ge, X., \& Land, S. M. (2003). Scaffolding students' problem-solving processes in an ill-structured task using question prompts and peer interactions. Educatioanl Technology Research and Development, 51(1), 21-38.

Graesser, A. C., McNamara, D. S., \& VanLehn, K. (2005). Scaffolding deep comprehension strategies through point\&query, autotutor, and iSTART. Educational Psychologist, 40, 225-234.

Granello, D. H. (2001). Promoting cognitive complexity in graduate written work: Using Bloom's taxonomy as a pedagogical tool to improve literature reviews. Counselor Education and Supervision, 40(4), 292-307.

Greene, B. A., \& Land, S. M. (2000). A qualitative analysis of scaffolding use in a resource-based learning environment involving the World Wide Web. Journal of Educational Computing Research, 23(2), 151-179.

Grolnick, W. S., \& Ryan, R. M. (1987). Autonomy in children's learning: An experimental and individual difference investigation. Journal of Personality and Social Psychology, 52, 890-898.

Hsiao, I. H., Sosnovsky, S., \& Brusilovsky, P. (2010). Guiding students to the right questions: Adaptive navigation support in an e-learning system for Java programming. Journal of Computer Assisted Learning, 26(4), 270-283. doi: 10.1111/j.1365-2729.2010.00365.x

Keefe, J. W. (1991). Learning style: Cognitive and thinking skills. Reston, VA: National Association of Secondary School Principals.

Keller, J.M. (2010). Motivational design for learning and performance. New York, NY: Springer.

Kelly, D. (2008). Adaptive versus learner control in a multiple intelligence learning environment. Journal of Educational Multimedia and Hypermedia, 17(3), 307-336.

Kenny, C., \& Pahl, C. (2009). Intelligent and adaptive tutoring for active learning and training environments. Interactive Learning Environments, 17(2), 181-195. doi: 10.1080/10494820802090277

Kim, C. (2012). The role of affective and motivational factors in designing personalized learning environments. Educational Technology Research \& Development, 60, 563-584. 
Lajoie, S. P., \& Azevedo, R. (2006). Teaching and learning in technology-rich environments. In P. Alexander \& P. Winne (Eds.), Handbook of educational psychology (2nd ed., pp. 803-821). Mahwah, NJ: Erlbaum.

Land, S., \& Zembal-Saul, C. (2003). Scaffolding reflection and articulation of scientific explanations in a data-rich, project-based learning environment: An investigation of progress portfolio. Educational Technology Research \& Development, 51(4), 65-84.

Lo, J.-J., Chan, Y.-C., \& Yeh, S.-W. (2012). Designing an adaptive web-based learning system based on students' cognitive styles identified online. Computers \& Education, 58(1), 209-222. doi: 10.1016/j.compedu.2011.08.018

MacGregor, S. K., \& Lou, Y. (2004). Web-based learning: How task scaffolding and web site design support knowledge acquisition. Journal of Research on Technology in Education, 37(2), 161-175.

Magoulas, G. D. , Papanikolaou, K., \& Grigoriadou, M. (2003). Adaptive web-based learning: Accommodating individual differences through system's adapation. British Journal of Educational Technology, 34(4), 511-527.

Mampadi, F., Chen, S. Y., Ghinea, G., \& Chen, M.-P. (2011). Design of adaptive hypermedia learning systems: A cognitive style approach. Computers \& Education, 56(4), 1003-1011. doi: 10.1016/j.compedu.2010.11.018

Papanikolaou, K. A., Grigoriadou, M., Kornilakis, H., \& Magoula, G. D. (2003). Personalising the inter-action in a web-based educational hypermedia system: The case of INSPIRE. User-Modeling and User-Adapted Interaction, 13(3), 213-267.

Park, S., Lee, G., \& Kim, M. (2009). Do students benefit equally from interactive computer simulations regardless of prior knowledge levels? Computers \& Education, 52, 649-655.

Peredo, R., Canales, A., Menchaca, A., \& Peredo, I. (2011). Intelligent web-based education system for adaptive learning. Expert Systems with Applications, 38(12), 14690-14702. doi: 10.1016/j.eswa.2011.05.013

Pintrich, P., \& Schunk, D. H. (1996). Motivation in education: Theory, research, and applications. Englewood Cliffs, NJ: Prentice-Hall.

Puntambekar, S., \& Hubscher, R. (2005). Tools for scaffolding students in a complex learning environment: What have we gained and what have we missed? Educational Psychologist, 40, 1-12.

Quintana, C., Meilan, Z., \& Krajcik, J. (2005). A framework for supporting metacognitive aspects of online inquiry through software-based scaffolding. Educational Psychologist, 40, 235-244.

Rasmussen, K.L., \& Davidson-Shivers, G.V. (1998). Hypermedia and learning styles: Can performance be influenced? Journal of Multimedia and Hypermedia, 7(4), 291-308.

Reigeluth, C. M. (1996). A new paradigm of ISD? Educational Technology \& Society, 36(3), 13-20.

Rey, G. D. (2010). Instructional advice, time advice and learning questions in computer simulations. Australasian Journal of Educational Technology, 26(5), 675-689.

Rosenshine, B., \& Meister, C. (1992). The use of scaffolds for teaching higher-level cognitive strategies. Educational Leadership, 49(7), 26-33.

Ryan, R.M., \& Deci, E.L. (2000). Self-determination theory and the facilitation of intrinsic motivation, social development, and well-being. American Psychologist, 55, 68-78.

Ryan, R.M., \& Deci, E.L. (2002). An overview of self-determination theory. In E. L. Deci \& R. M. Ryan (Eds.), Handbook of self-determination research (pp. 3-33). Rochester, NY: University of Rochester Press.

Shapiro, A. M. (1999). The relationship between prior knowledge and interactice overviews during hypermedia-aided learning. Journal of Educational Computing Research, 20, 143-167.

Shute, V., \& Towle, B. (2003). Adaptive e-learning. Educational Psychologist, 38(2), 105-114.

Sins, P. H. M., Savelsbergh, E. R., \& Van Joolingen, W. R. (2005). The difficult process of scientific modelling: An analysis of novices' reasoning during computer-based modelling. International Journal of Science Education, 27, 1695-1721.

Sins, P. H.M., Van Joolingen, W. R., Savelsbergh, E. R., \& Van Hout-Wolters, B. (2008). Motivation and performance within a collaborative computer-based modeling task: Relations between students' achievement goal orientation, self-efficacy, cognitive processing, and achievement. Contemporary Educational Psychology, 33, 58-77.

Specht, M., \& Oppermann, R. (1998). ACE: Adaptive CourseWare Environment. New Review of HyperMedia \& MultiMedia, 4, 141-161. 
Tseng, J. C. R., Chu, H.-C., Hwang, G.-J., \& Tsai, C.-C. (2008). Development of an adaptive learning system with two sources of personalization information. Computers \& Education, 51(2), 776-786.

Vallerand, R. J., Pelletier, L. G., Blais, M. R., Briere, N. M., Senecal, C., \& Vallieres, E.F. (1992). The academic motivation scale: A measure of intrinsic, extrinsic, and amotivation in education. Educational and Psychological Measurement, 52, 1003-1017.

Van den Boom, G. , Paas, F., Van Merrienboer, J. J.G., \& Van Gog, T. (2004). Reflection prompts and tutor feedback in a web-based learning environment: Effects on students' self-regulated learning competence. Computers in Human Behavior, 20, 551-567.

Vygotsky, L. S. (1978). Mind in society. Cambridge: Harvard University Press.

Weiner, B. (1990). History of motivational research in education. Journal of Educational Psychology, 82(4), 616-622.

Whipp, J. L., \& Chiarelli, S. (2004). Self-regulation in a web-based course: A case study. Educational Technology Research \& Development, 52(4), 5-22.

Wood, P., Bruner, J., \& Ross, G. (1976). The role of tutoring in problem solving. Journal of Child Development and Psychiatry., 17(89-100).

Zhu, E. (2006). Interaction and cognitive engagement: An analysis of four asynchronous online discussions. Instructional Science, 34, 451-480.

Corresponding author: Ching-Huei Chen, chhchen@cc.ncue.edu.tw

Australasian Journal of Educational Technology (C) 2014.

Please cite as: Chen, C. (2014). An adaptive scaffolding e-learning system for middle school students' physics learning. Australasian Journal of Educational Technology, 30(3), 342-355. 